\title{
Overcoming Language Barriers, Enhancing Collaboration With Interpreters - An Interprofessional Learning Intervention (Interpret2improve)
}

Franziska Krampe

Childrens Hospitals Harlaching and Schwabing, Technical University Munich

Götz Fabry

Albert-Ludwigs-University Freiburg

Thorsten Langer ( $\boldsymbol{\nabla}$ thorsten.langer@uniklinik-freiburg.de )

University Hospital Freiburg

\section{Research Article}

Keywords: interprofessionalism, language barriers, cultural competence, interpreters, education, paediatrics

Posted Date: September 20th, 2021

DOl: https://doi.org/10.21203/rs.3.rs-821160/v1

License: (c) (1) This work is licensed under a Creative Commons Attribution 4.0 International License. Read Full License

Version of Record: A version of this preprint was published at BMC Medical Education on March 12th, 2022. See the published version at https://doi.org/10.1186/s12909-022-03213-0. 


\section{Abstract}

Background: Language barriers (LB) are common in patient care. They can negatively impact the quality of care, and increase costs. LB can be overcome by using interpreters. However, collaboration with interpreters is a professional activity which can and needs to be learnt. Interpret2/mprove is an innovative educational intervention where medical and nursing students learn together how to address LB and effectively collaborate with interpreters.

Methods: The three-hour course has two parts: After a short introduction on the relevance of LB and resulting issues of patient safety etc., students in interprofessional teams of two practice conversations with non-German-speaking simulated patients and professional interpreters. The course is evaluated in a pre-post format with the Freiburg Questionnaire for Interprofessional Learning Evaluation which has been validated in prior studies.

Results: 51 students (thirty of the participants were medical students, 21 participants were students in nursing care) participated from 11/2016-07/2018. Overall, the course was very well received (mean 1.73 (SD 0,85 ) on a five point scale: $1=$ very good, $5=$ insufficient). The evaluation by medical and nursing students differed significantly. 14 out of 21 items show a self-assessed increase in interprofessional knowledge or skills.

Conclusions: Students felt that their skills in adressing LB by effectively collaborating with interpreters increased during this interprofessional format. Further studies are needed to obtain further evidence beyond self-assessment and regarding the longterm outcomes.

\section{Background}

Healthcare systems in many countries are faced with increased immigration which leads to a growing ethnic, cultural and linguistic diversity [1]. In 2018, one billion individuals have been on the move or have moved to another country worldwide. In the European Union, 36.9 million people living in an EU Member State were born outside of the EU-28 in 2017 [2]. In Germany, 23.4\% of inhabitants are of migrant origin, i.e. at least one parent was born in another country. Among children under 15 years of age the proportion is $37,5 \%$ [3].

As a consequence of an increasing linguistic diversity, language barriers (LB) present an important challenge to many healthcare systems. LB can impair access to health care service for patients who are not proficient in the language of the societies' majority [4]. LB have a negative impact on the quality of care[5-7] and patient safety $[8,9]$ and increase costs through more frequent unnecessary testing, avoidable hospitalizations and longer hospital stays [10-14]. Thus they contribute to health disparities in many societies [15].

LB can impair the quality of communication between patient and clinician in numerous occasions such as history taking, counselling or patient education [16]. Clinicians often recognize language barriers late 
in the care process [17].

In fact, even when interpreters are available at low or no costs, many clinicians decide not to collaborate with them [18-20]. It is common to use informal interpreters like family members or hospital employees for interpreting. However, informal interpreters make more mistakes than professional interpreters which can lead to more treatment errors $[6,21]$. Further, informal interpreters rarely take on a neutral role and exert a stronger influence on the course of the conversation [22, 23]. Finally, many clinicians rate themselves to be competent in working with interpreters while in fact they are not [24].

However, even with professional interpreters being present, communication in a triad consisting of patient, clinician and interpreter differs significantly from the dyadic structure in most languageconcordant encounters $[25,26]$. Despite the traditional view held by many clinicians and interpreters themselves [27], interpreters in the health care setting do not act merely as conduits or "language switching operators" transforming messages from one language to another [28]. In fact, linguistic research has shown that interpreters act as co-producers of the conversation. For example, Bolden demonstrated how interpreters "assist" clinicians in taking a history. Interpreters in her study not just interpreted back and forth between clinician and patient, but also asked additional questions to objectify symptoms and by conveying the information to the doctor in a medically framed way [29]. While interpreters take on a supporting role in many situations, the opposite has been reported, too. In an analysis of video-recordings of routine diabetes review consultations, Seale et al showed that interpreters frequently did not translate patients' utterances they deemed unrelated to the diabetes [30].

As complexity of a conversation increases when interpreters are present it seems important that clinicians are adequately prepared for such encounters. One way to address this issue is education of care providers. Several educational programs for physicians, medical students, physician assistant students and pharmacy students have shown to increase the likelihood to work with professional interpreters and to improve the quality of their collaboration [31-39]. However, opportunities for clinicians to develop such competencies are still scarce. A survey investigating the medical curricula in 12 European countries showed that abilities to work with interpreters are rarely included [40]. For nurses and clinical psychologists, the authors are unaware of any published studies on training programs. In Germany, the need for more educational offerings in the context of cultural competence and global health including the collaboration with interpreters has been acknowledged in a recent position paper [41].

To address this gap we developed an educational intervention bringing together final year medical students and 2nd year students in paediatric nursing in an interprofessional learning experience. Interprofessional Education (IPE) is defined as learning together, from and about each other from members of two or more professional groups to activate effective collaboration and improve the care of patients [42]. We found an IPE approach particularly suited for this topic because conversations with interpreters are interprofessional per se. Moreover, several health professions deal with language barriers in differing contexts which offers an interesting learning opportunity as different perspectives can enrich the learning experience. The intervention aims at 
- Increasing awareness of the role of LB with regard to the quality of medical and nursing care

- Teaching strategies how to recognize LBs

- Teaching strategies how to collaborate with interpreters more effectively in a simulated scenario

- Providing insights how LBs specifically influence the work of medical and nursing staff, respectively

In this paper, we describe the intervention and present the results of the evaluation study.

\section{Methods}

The aim of this study was to evaluate the feasibility of the collaborative learning module and to evaluate its effect from the learners' perspectives. The study was designed as a mixed methods study using qualitative and quantitative data in a pre/post evaluation.

Theoretical and didactic framework:

The course development was conducted using the Program to Enhance Relational and Communication Skills (PERCS) as a didactic framework. The PERCS pedagogy is based on the concepts of validating clinicians' existing relational capacities, emphasizing moral dimensions of care, suspending hierarchy, and creating a safe learning environment $[43,44]$. Another important element is the use of simulated patients (SP) portraying the roles of patients and family members. The SP have received special training to assist with debriefing and give participants direct feedback on their communication styles and approaches $[45,46]$. We chose PERCS as a framework as it combines important elements of relational learning with the opportunity to facilitate interprofessional discourse in the context of interprofessional education. The learning objectives are displayed in Table 1.

Table 1

Learning objectives of the course

After the seminar the participants can

explain the importance of language barriers for the quality of care in medicine and nursing care,

\& work effectively with interpreters,

get to explain the relevance of interprofessional cooperation and

describe the professional roles of colleagues from other professions

Description of the intervention:

The course is designed as a three-hour seminar. It is part of a longitudinal interprofessional curricular thread at the Faculty of Medicine Freiburg [47]. The data presented here were collected from winter term 2016/2017 to summer term 2018. Both medical and nursing students learn at University Hospital in Freiburg, Germany. In Germany, medical training is a six-year-program. The participating medical students are all in the final year of training in which they are part of care teams and work under supervision of 
senior medical staff. The training as a nurse takes three years. The participants are in their $2 \mathrm{nd}$ and $3 \mathrm{rd}$ year of training in which practical assignments and theory units alternate. Both professions have had first experiences in patient contact at the time of the course. The interprofessional teaching team consists of a paediatrician with expertise on social paediatrics and language barriers, a medical psychologist with a focus on research on communication, the head of the local interpreter pool, as well the trainer for the simulated patients who also has a background in nursing. The language of instruction is German. The participants were invited to the course by email. Participation was voluntary.

Content and Structure of the course (see Fig. 1):

\section{Theoretical introduction}

The participants learn about the relevance of language barriers in medicine and nursing in terms of quality of care and patient safety. Important topics include the frequency of language barriers, the diversity of languages spoken in Germany, the ethics of language barriers regarding equal treatment, legal aspects regarding the validity of informed consent conversations.

\section{Groupwork and discussion}

In a subsequent exercise, participants are invited to share their own experiences in the context of the topic and to develop ideas on how to recognize and overcome language barriers in everyday clinical practice. The results are visualized and serve as a starting point for the following discussion focusing on differences and similarities among participants' experiences. During this group discussion, the participants also learn about different variants of interpreting (telephone interpreting, professional vs. non-professional interpreters) and the respective advantages and disadvantages associated with the different options and the potentially resulting problems.

\section{Practical exercise / simulation}

Next, participants have the opportunity to practice an enacted, interpreted conversation with a nonGerman native speaking SP and the linguistically appropriate interpreters. SP cases include informing a mother about the HPV vaccination of her daughter or taking the history of a toddler with gastroenteritis and a diaper rash who is presented in the emergency department by his grandmother (see appendix). The SPs are trained to portray these cases authentically. We offered the case studies in Russian, Turkish, Spanish and Portuguese. Thus, participants experience the similarities and differences between an interpreter-mediated and a language-concordant conversation. We offered two simulations per teaching session in which we used different cases. The simulation interviews can either be done by a participant alone or as an interprofessional team consisting of a medical student and a student of paediatric nursing. The participants are instructed to focus not only on the medical issue at hand (e.g. differential diagnoses of gastroenteritis or data regarding the incidence of HPV-associated diseases) but are also encouraged to address the psychosocial cues offered by the SPs.

\section{Debriefing and feedback}


After the simulations, participants of the role-play engage in a debriefing exercise with the SPs, the group and course leaders [48]. On the one hand, this discussion serves as feedback for participants regarding their performance. On the other hand, special features which emerged during the simulation are being reflected in the group for a more general discussion. Typical topics include the introduction of interpreters in the conversation with patients, the seating arrangement in interpreter-supported conversation or the use of short phrases during the conversation. After participating in or witnessing the simulation, participants are also able to ask interpreters questions e.g. regarding their interpretation of role-neutrality. In this way, participants engage in an interprofessional, reflective discussion about behavioural and context factors which should be considered by medical and nursing staff in order to optimize the quality of the interaction with interpreters and patients.

Evaluation: The intervention was evaluated by participants in a pre-post design using both online and paper/pencil questionnaires. Questionnaires were based on previously published PERCS surveys[44] and the Freiburg Questionnaire for Interprofessional Learning Evaluation ("FILE")[49] and included questions on demographic characteristics. The items from PERCS surveys focus on the learner's experience of the workshop ( 5 closed and 5 open questions). The FILE is an instrument for the self-assessment of different aspects of interprofessional competencies. It comprises 21 items and includes the following scales: relevance of interprofessionality (10 items), understanding of one's role (5 items), ability to work in a team ( 6 items), team competence ( 5 items). The items are rated on a five-point Likert scale ( $1=$ very good, $5=$ insufficient) [49].

Analysis: The evaluation was carried out by means of descriptive statistics (absolute and relative frequencies, group comparisons by T-test, Bonferroni correction) as well as an orienting qualitative content analysis of the free text answers [50]. For the statistical analysis we used SPSS (version 25.0 and 27.0, Armonk, NY: IBM Corp.).

\section{Results}

\section{Demographic data of the participants}

Fifty-one students participated in the course. Forty-three (84\%) of the participants were female. Thirty $(59 \%)$ of the participants were medical students, 21 participants (41\%) were students in nursing care (Table 2).

Table 2

Description of the sample

\begin{tabular}{|lll|}
\hline & Medical students & Nursing care students \\
\hline Female & 22 & 21 \\
\hline Male & 8 & 0 \\
\hline Age & $22-36$ years $(M=26,84$ years $)$ & $20-48$ years $(M=23,4$ years $)$ \\
\hline
\end{tabular}


On average the participants were 25.5 years of age (SD \pm 4.7 years).

Overall assessment of the course: The course was rated with 1.73 (SD \pm 0.85 ) overall. The ratings improved after year 1 (winter semester 2016/17: $m=2.60(S D \pm 1.27$ ), summer semester 2017: $m=1.4$ $(S D \pm 0.5$; summer semester $2018 m=1.69(S D \pm 0.6(p<0.01)$

Medical students rated the course better than nursing students (medical students: 1.5 , nursing students: $2.1, p=0.02$ ). Some nursing students stated in the open-ended questions that they rarely take a history in their training and thus felt overwhelmed in the simulated conversations (see also Fig. 2).

$98 \%$ of the participants were in favour of a continuation of the course. This was supported by participants' free text comments, e.g. "continue this training, it is a very important topic which is increasingly needed in clinics". A paediatric nursing care students quoted "I think it would be good if there were more interprofessional learning opportunities"

The teachers were rated at 1.43 (SD \pm 0.816$), n=49$. No significant differences were found in the assessment of teachers between the individual professions.

\section{Evaluation of the interprofessional learning experience}

In the pre/post comparison, participants showed an increase in all four scales covered by the FILE ( $p<$ 0.002 (see Fig. 3).

When looking at single items, 14 out of 21 FILE items show significant results regarding higher selfassessed competence after the course. The participants rated the item "The teachers were good representatives of interprofessional cooperation" (rated on a five-point Likert scale from " $1=$ does not apply at all" to $5=$ "fully agrees") after the course $m=4.60, n=45(S D \pm 0.75)$. The item "My interest in interprofessional learning has grown through the event" was rated post as $m=4.50$ (SD \pm 0.61 ) with no pre item regarding this question. The item "Through the event, my role in the interprofessional team became clearer" was rated post as $m=4.08$ ( $S D \pm 0.86)$. These findings are supported by the answers in the open-ended questions. Participants stated that "working together interdisciplinary for the patient!" is important and they liked how the course "brings together different professional groups".

Evaluation of the learning experience with regard to language barriers and interpreters: Medical students said after the course they learned that "Interpreters translate everything you say and what everyone in the room says. They stay strictly in the background". Another student stated: "How to conduct the interview: seating arrangement, short sentences, that a preliminary conversation with the interpreters is important, explain to the relative what happens, seek consent; declare confidentiality to the patient" as well as to have "eye contact with patient - not with the interpreter" were two of the main learning issues for medical and paediatric nursing care students. Several participants stated the want to "demand interpreters actively for better treatment quality" in the future. 


\section{Discussion}

We found that bringing together medical and nursing student to learn about the relevance of language barriers and to improve collaboration with interpreters is both feasible and valued by participants.

The course was very well received by the participants with an overall grade of 1.73 , with a significant difference in the rating of medical students compared to students in (child) nursing. This difference can be explained by the fact that the case studies used during the role-plays in the first two seminars were not sufficiently adjusted to the nursing students' level of experience. Subsequently, we revised the gastroenteritis case and expanded it by specific topics of care such as hygiene and wound care. In the following seminars, an increase of the satisfaction with the case studies by the nursing students and because of that of the evaluation of the course in general between the winter term 2016/17 and the following semesters could be observed.

Regarding the learning objectives, participants stated that they learned about the importance of language barriers for the quality of care and how to work effectively with interpreters during the course. This is in line with evidence from other studies, showing that training for medical staff, in which participants learned about the importance of language barriers and practiced with interpreters, increases the willingness to work with professional interpreters $[36,51]$ as well as physicians' respective competences [37]. Jacobs et al. also report this result from a one-and-a-half-hour training course with a similar curriculum for medical students [32].

Our intervention aimed at framing interpreter-supported conversations as an interprofessional activity. This was reflected by the teaching team which included health care professionals from different backgrounds and a trained interpreter. The positive evaluation of the course and the teaching team seem to acknowledge this setting. The relevance of interprofessionalism in healthcare was also highly valued with a significant increase in the before and after evaluation. After the course, the participants said that they critically reflected their actions in the interprofessional team in order to understand their own roles better and they also stated that learning together had a positive impact on their opinion about other health professions. This is in line with findings from prior studies suggesting that participants in an interprofessional course gained a clearer understanding of their role, critically reflected their actions in the interprofessional team, worked well with other professional groups and learned about their personal limits [52-57].

Although, IPE has gained increasing attention among educators in many countries including Germany its implementation of learning opportunities can be challenging for conceptual and organizational reasons [56-72]. The course presented here requires resources for the development of cases and the training of SPs. However, it requires a relatively short teaching time and little teaching material. Nevertheless, recruiting participants was partly challenging due to the optional nature of the training, many compulsory lessons in students' curricula and perhaps due to a lack of reflection on the importance of the subject and the need to be trained in interpreting. 
Limitations of the present study are the relatively small number of participants with $n=51$ as well as participation in the course on a voluntary basis. Because of that influencing the results might be biased by prior interest in the subject and other motivational factors. Furthermore, the reported learning success is based on the participants' self-assessment rather than objective assessment. This should be addressed in follow-up studies.

The present interprofessional course, as part of a longitudinal thread on interprofessional competences at the Faculty of Medicine Freiburg [47], is, to our knowledge, unique in Germany.

\section{Conclusion}

Students felt that their skills in adressing LB by effectively collaborating with interpreters increased during this interprofessional format. The handling of LB and the effective collaboration with interpreters seems very well suited for an interprofessional course for medical and nursing students as well as other health professionals. With optional participation and a high density of other (compulsory) teaching lessons, recruiting participants is a challenge. Compulsory training courses for medical professionals dealing with language barriers and sensitization in the use of interpreters have been published, for example, in the US $[31,33-35,38]$ and would be desirable in Germany as well. The extent to which the course contributes to a change in care practice should be further explored.

\section{Appendix}




\section{Appendix A: Case study 1}

Background: Ms. Gomez is 48 years old and from Madrid. She has been living in Freiburg for 8 months. She came to Germany with her husband and two children (11 and 7 years) as part of a research stay for two years.

Characteristics of the mother: Attentive, questioning and interested in conversation. I want to make the right decision for your daughter.

\section{External appearance: well-groomed appearance}

Taking the history of the patient: Ms. Gomez has arranged a consultation to discuss the pros and cons of having an HPV vaccine for her older daughter Paula. She wants to have the first conversation without the daughter, as she finds it too early to discuss cervical cancer and sexual intercourse with her daughter. Instead, she wants to first be clear about whether she should get the vaccine.

Behavior in conversation: Mrs. Gomez tries to be polite. She does not want to understand her need for information as distrust. Although she is otherwise a self-confident and analytically thinking woman, in the current situation in the consultation, she is a little uncertain. At first, it is unpleasant for her not to speak enough German; she speaks a few words of German.

Task/situation description for the lessons: As a medical student, they are currently completing a rotation in the outpatient clinic during the practical year. They conduct the consultation and refer to further questions, to the specialist, which comes later. As part of a pilot project, a Spanish-speaking Spanish interpreter works at the clinic, who can provide flexible and long-term planning. The registration informes you that Mrs. Gomez does not speak German, her mother tongue is Spanish and the interpreter is currently available.

\section{Case study HPV vaccine}


Appendix B: Case study 2

Background: Viktor is 2.5 years old and the second child of the Ivanov family. The family of three, originally from Siberia, has been living in Germany for 8 years. One year ago, the grandmother of Viktor (the mother of the child's father) moved to Germany and lives in a neighboring apartment. Currently, Viktor's parents have gone to Regensburg for a wedding and Viktor's grandmother takes care of him. So far she hardly had any opportunity to learn German.

Taking history and physical examination: Viktor has barely been drinking for three days. He vomits 23 times/day and has watery diarrhea (4-5/d). The skin around the anus and in the groin is very red and occasionally bloody. Viktor screams as soon as he empties his chair and cleans the buttocks. Ms. Ivanova has so far often wrapped, thoroughly cleansed the skin with soap and then creamed with a moisturizing lotion.

Characteristics of Ms Ivanova: Uncertain but determined in the care of her child.

Behavior in conversation: Ms. Ivanova comes to the hospital because she is very worried about her grandchild. He has never had diarrhea and vomiting, and he does not know how to drink. She is afraid he might die if nothing is done. She knows she needs help. At the same time, she never has been alone in a German hospital. It makes her uncomfortable that she hardly speaks German. Maybe there is a doctor or a sister who speaks her language?

Task for nursing student / situation description: As part of their training they are employed in the outpatient clinic of the Children's Hospital. After examining the child by the doctor, you should advise Mrs. Ivanova on skin care in the nappy area. They primarily inquire how Ms. Ivanova has done the care so far and give her targeted recommendations. Within the framework of a pilot project, a Russian interpreter works in the clinic, which you can use flexibly and without any preliminary planning.

\section{Case study gastroenteritis}

\section{Declarations}

Ethics approval and consent to participate: The study was conducted according to national relevant guidelines and data protection regulations. All data were collected anonymously. Data analyzed in this study have been collected as part of the routine course evaluation for quality asurance purposes.

Consent for publication: Not applicable

Availability of data and materials: The datasets used and/or analysed during the current study are available from the corresponding author on reasonable request.

Competing interests: The authors declare that they have no competing interests.

Funding: The course was funded by the german "Ministerium für Wissenschaft, Forschung und Kunst Baden-Württemberg" in the "Sonderlinie Medizin - Förderlinie Lehre", teaching project: „Interpret2Improve“ - Verbesserte Kommunikation mit Patienten durch Erkennen von Sprachdifferenzen und kompetenten Einsatz von Dolmetschern im interprofessionellen Team, number: 3091321728

Authors' contributions: FK did mainly the statistical analysis and was a major contributor in writing the manuscript. GF helped with the statistical analysis and the project administration. TL did mainly the 
project administration and also helped with the statistical analysis and writing the manuscript. All authors read and approved the final manuscript.

Acknowledgements: Not applicable.

\section{References}

1. Abubakar I, Aldridge RW, Devakumar D, Orcutt M, Burns R, Barreto ML, et al. The UCL-Lancet Commission on Migration and Health: The health of a world on the move. The Lancet. 2018;392:2606-54. doi:10.1016/S0140-6736(18)32114-7.

2. Eurostat. Migration and migrant population statistics Secondary Migration and migrant population statistics. 2018. https://ec.europa.eu/eurostat/statistics-explained/index.php? title=Migration_and_migrant_population_statistics.

3. Bundesamt S. Bevölkerung und Erwerbstätigkeit. Bevölkerung mit Migrationshintergrund Ergebnisse des Mikrozensus 2017 -, 2018 2017-2018.

4. Cohen AL, Christakis DA. Primary language of parent is associated with disparities in pediatric preventive care. J Pediatr. 2006;148:254-8. doi:10.1016/j.jpeds.2005.10.046.

5. Karliner LS, Jacobs EA, Chen AH, Mutha S. Do professional interpreters improve clinical care for patients with limited English proficiency? A systematic review of the literature. Health Serv Res. 2007;42:727-54. doi:10.1111/j.1475-6773.2006.00629.x.

6. Flores G, Laws MB, Mayo SJ, Zuckerman B, Abreu M, Medina L, Hardt EJ. Errors in Medical Interpretation and Their Potential Clinical Consequences in Pediatric Encounters. Pediatrics. 2003;111:6-14. doi:10.1542/peds.111.1.6.

7. Cohen AL, Rivara F, Marcuse EK, McPhillips H, Davis R. Are Language Barriers Associated With Serious Medical Events in Hospitalized Pediatric Patients? Pediatrics. 2005;116:575-9. doi:10.1542/peds.2005-0521.

8. Johnstone M-J, Kanitsaki O. Culture, language, and patient safety: Making the link. Int J Qual Health Care. 2006;18:383-8. doi:10.1093/intqhc/mzl039.

9. Aboumatar HJ, Chang BH, Al Danaf J, Shaear M, Namuyinga R, Elumalai S, et al. Promising Practices for Achieving Patient-centered Hospital Care: A National Study of High-performing US Hospitals. Med Care. 2015;53:758-67. doi:10.1097/MLR.0000000000000396.

10. Lindholm M, Hargraves JL, Ferguson WJ, Reed G. Professional Language Interpretation and Inpatient Length of Stay and Readmission Rates. Journal of General Internal Medicine. 2012;27:1294-9. doi:10.1007/s11606-012-2041-5.

11. Abbato S, Greer R, Ryan J, Vayne-Bossert P, Good P. The Impact of Provision of Professional Language Interpretation on Length of Stay and Readmission Rates in an Acute Care Hospital Setting. Journal of Immigrant and Minority Health 2018. doi:10.1007/s10903-018-0830-6.

12. Goldman RD, Amin P, Macpherson A. Language and length of stay in the pediatric emergency department. Pediatr Emerg Care. 2006;22:640-3. doi:10.1097/01.pec.0000227865.38815.ec. 
13. Hampers LC, Cha S, Gutglass DJ, Binns HJ, Krug SE. Language Barriers and Resource Utilization in a Pediatric Emergency Department. Pediatrics. 1999;103:1253-6. doi:10.1542/peds.103.6.1253.

14. Hampers LC, McNulty JE. Professional Interpreters and Bilingual Physicians in a Pediatric Emergency Department. Arch Pediatr Adolesc Med. 2002;156:1108. doi:10.1001/archpedi.156.11.1108.

15. Levin ME. Language as a barrier to care for Xhosa-speaking patients at a South African paediatric teaching hospital. South African Medical Journal. 2006;96:1076-9.

16. Ngo-Metzger Q, Sorkin DH, Phillips RS, Greenfield S, Massagli MP, Clarridge B, Kaplan SH. Providing High-Quality Care for Limited English Proficient Patients: The Importance of Language Concordance and Interpreter Use. Journal of General Internal Medicine. 2007;22:324-30. doi:10.1007/s11606-0070340-z.

17. van Rosse F, Bruijne M de, Suurmond J, Essink-Bot M-L, Wagner C. Language barriers and patient safety risks in hospital care. A mixed methods study. Int J Nurs Stud. 2016;54:45-53. doi:10.1016/j.jijnurstu.2015.03.012.

18. Kale E, Syed HR. Language barriers and the use of interpreters in the public health services. A questionnaire-based survey. Patient Educ Couns. 2010;81:187-91. doi:10.1016/j.pec.2010.05.002.

19. Bischoff A, Bovier PA, Isah R, Françoise G, Ariel E, Louis L. Language barriers between nurses and asylum seekers: Their impact on symptom reporting and referral. Social Science \& Medicine. 2003;57:503-12. doi:10.1016/S0277-9536(02)00376-3.

20. Jacobs EA, Shepard DS, Suaya JA, Stone E-L. Overcoming Language Barriers in Health Care: Costs and Benefits of Interpreter Services. Am J Public Health. 2004;94:866-9. doi:10.2105/AJPH.94.5.866.

21. Flores $G$. The impact of medical interpreter services on the quality of health care: A systematic review. Med Care Res Rev. 2005;62:255-99. doi:10.1177/1077558705275416.

22. Leanza Y, Boivin I, Rosenberg E. Interruptions and resistance: A comparison of medical consultations with family and trained interpreters. Soc Sci Med. 2010;70:1888-95. doi:10.1016/j.socscimed.2010.02.036.

23. Rosenberg E, Seller R, Leanza Y. Through interpreters' eyes: Comparing roles of professional and family interpreters. Patient Educ Couns. 2008;70:87-93. doi:10.1016/j.pec.2007.09.015.

24. Hudelson P, Perneger T, Kolly V, Perron NJ. Self-assessed competency at working with a medical interpreter is not associated with knowledge of good practice. PLoS ONE. 2012;7:e38973. doi:10.1371/journal.pone.0038973.

25. Swinglehurst D, Roberts C, Li S, Weber O, Singy P. Beyond the 'dyad': A qualitative re-evaluation of the changing clinical consultation. BMJ Open. 2014;4:e006017. doi:10.1136/bmjopen-2014-006017.

26. Hsieh E. Bilingual health communication: Working with interpreters in cross-cultural care. New York; 2016.

27. Sleptsova M, Hofer G, Marcel E, Grossman P, Morina N, Schick M, et al. Wie verstehen Dolmetscher ihre Rolle in medizinischen Konsultationen und wie verhalten sie sich konkret in der Praxis? [What do 
Interpreters Understand as their Role in a Medical Consultation and How do they Carry it out in Reality?]. Psychother Psychosom Med Psychol. 2015;65:363-9. doi:10.1055/s-0035-1554691.

28. Angelelli CV. Medical Interpreting and Cross-cultural Communication. Edinburgh: Cambridge University Press; 2004.

29. Bolden GB. Toward Understanding Practices of Medical Interpreting: Interpreters' Involvement in History Taking. Discourse Studies. 2000;2:387-419. doi:10.1177/1461445600002004001.

30. Seale C, Rivas C, Al-Sarraj H, Webb S, Kelly M. Moral mediation in interpreted health care consultations. Soc Sci Med. 2013;98:141-8. doi:10.1016/j.socscimed.2013.09.014.

31. Constance J. Shriner, Daniel P. Hickey. Teaching and Assessing Family Medicine Clerks' Use of Medical Interpreters. Family Medicine. 2008;40:313-5.

32. Jacobs EA, Diamond LC, Stevak L. The importance of teaching clinicians when and how to work with interpreters. Patient Educ Couns. 2010;78:149-53. doi:10.1016/j.pec.2009.12.001.

33. Kalet AL, Mukherjee D, Felix K, Steinberg SE, Nachbar M, Lee A, et al. Can a web-based curriculum improve students' knowledge of, and attitudes about, the interpreted medical interview? Journal of General Internal Medicine. 2005;20:929-34. doi:10.1111/j.1525-1497.2005.0193.x.

34. Marion GS, Hildebrandt CA, Davis SW, Marín AJ, Crandall SJ. Working effectively with interpreters: A model curriculum for physician assistant students. Med Teach. 2008;30:612-7. doi:10.1080/01421590801986539.

35. McEvoy M, Santos MT, Marzan M, Green EH, Milan FB. Teaching Medical Students How to Use Interpreters: A Three Year Experience. Medical Education Online. 2017;14:4507. doi:10.3402/meo.v14i.4507.

36. Bischoff A, Perneger T, Bovier P, Loutan L, Stalder H. Improving communication between physicians and patients who speak a foreign language. $\mathrm{Br} J$ Gen Pract. 2003;53:541-6.

37. Kennedy CC, Rho JP. Using interpreters to teach. Medical Education. 2004;38:557. doi:10.1111/j.1365-2929.2004.01864.x.

38. Haack S. Engaging Pharmacy Students with Diverse Patient Populations to Improve Cultural Competence. Am J Pharm Educ. 2008;72:124. doi:10.5688/aj7205124.

39. Omoruyi EA, Dunkle J, Dendy C, McHugh E, Barratt MS. Cross Talk: Evaluation of a Curriculum to Teach Medical Students How to Use Telephone Interpreter Services. Acad Pediatr. 2018;18:214-9. doi:10.1016/j.acap.2017.11.010.

40. Sorensen J, Norredam M, Suurmond J, Carter-Pokras O, Garcia-Ramirez M, Krasnik A. Need for ensuring cultural competence in medical programmes of European universities. BMC Med Educ. 2019;19:21. doi:10.1186/s12909-018-1449-y.

41. Mews C, Schuster S, Vajda C, Lindtner-Rudolph H, Schmidt LE, Bösner S, et al. Cultural Competence and Global Health: Perspectives for Medical Education - Position paper of the GMA Committee on Cultural Competence and Global Health. GMS J Med Educ. 2018;35:Doc28. doi:10.3205/zma001174. 
42. World Health Organization. Framework for action on interprofessional education and collaborative practice. No. WHO/HRH/HPN/10.3. Geneva: World Health Organization, 2010.

43. Browning DM, Meyer EC, Truog RD, Solomon MZ. Difficult conversations in health care: Cultivating relational learning to address the hidden curriculum. Acad Med. 2007;82:905-13. doi:10.1097/ACM.0b013e31812f77b9.

44. Meyer EC, Brodsky D, Hansen AR, Lamiani G, Sellers DE, Browning DM. An interdisciplinary, familyfocused approach to relational learning in neonatal intensive care. Journal of Perinatology. 2011;31:212. doi:10.1038/jp.2010.109.

45. Bell SK, Pascucci R, Fancy K, Coleman K, Zurakowski D, Meyer EC. The educational value of improvisational actors to teach communication and relational skills: Perspectives of interprofessional learners, faculty, and actors. Patient Educ Couns. 2014;96:381-8. doi:10.1016/j.pec.2014.07.001.

46. Pascucci RC, Weinstock PH, O'Connor BE, Fancy KM, Meyer EC. Integrating actors into a simulation program: a primer. Simulation in healthcare: journal of the Society for Simulation in Healthcare. Journal of the Society for Simulation in Healthcare. 2014;9:120-6.

47. LongStl Freiburg. https://www.medstudek.uni-freiburg.de/studienganguebergreifendebereiche/kompetenzzentrum/bmbf-verbundprojekt-merlin/longitudinale-straenge.

48. Rudolph JW, Simon R, Dufresne RL, Raemer DB. There's No Such Thing as "Nonjudgmental" Debriefing: A Theory and Method for Debriefing with Good Judgment. Simulation in Healthcare. 2006;1:49.

49. Bergmann S, Giesler M. Evaluation interprofessioneller Lehrveranstaltungen mit FILE-: Freiburger Fragebogen für Interprofessionelle Lernevaluation. 2016. https://www.egms.de/static/en/meetings/gma2016/16gma212.shtml.

50. Graneheim U, Lundman B. Qualitative content analysis in nursing research: Concepts, procedures and measures to achieve trustworthiness. Nurse Education Today. 2004;24:105-12. doi:10.1016/j.nedt.2003.10.001.

51. Gerrish K, Chau R, Sobowale A, Birks E. Bridging the language barrier: The use of interpreters in primary care nursing. Health Soc Care Community. 2004;12:407-13. doi:10.1111/j.13652524.2004.00510.x.

52. Morphet J, Hood K, Cant R, Baulch J, Gilbee A, Sandry K. Teaching teamwork: An evaluation of an interprofessional training ward placement for health care students. Adv Med Educ Pract. 2014;5:197-204. doi:10.2147/AMEP.S61189.

53. Mellor R, Cottrell N, Moran M. "Just working in a team was a great experience... Student perspectives on the learning experiences of an interprofessional education program. J Interprof Care. 2013;27:292-7. doi:10.3109/13561820.2013.769093.

54. Jakobsen F, Larsen K, Hansen TB. This is the closest I have come to being compared to a doctor: Views of medical students on clinical clerkship in an Interprofessional Training Unit. Med Teach. 2010;32:e399-406. doi:10.3109/0142159X.2010.496009. 
55. Brewer ML, Stewart-Wynne EG. An Australian hospital-based student training ward delivering safe, client-centred care while developing students' interprofessional practice capabilities. J Interprof Care. 2013;27:482-8. doi:10.3109/13561820.2013.811639.

56. Ericson A, Masiello I, Bolinder G. Interprofessional clinical training for undergraduate students in an emergency department setting. J Interprof Care. 2012;26:319-25. doi:10.3109/13561820.2012.676109.

57. Krampe F, Peters S, Straub C, Bode S. Protecting children across borders - child protection in an international context (Germany/Switzerland) as an interprofessional teaching unit. GMS J Med Educ. 2020;37:1-21.

58. Lindblom P, Scheja M, Torell E, Astrand P, Felländer-Tsai L. Learning orthopaedics: Assessing medical students' experiences of interprofessional training in an orthopaedic clinical education ward. $J$ Interprof Care. 2007;21:413-23. doi:10.1080/13561820701401346.

59. Wilhelmsson M, Pelling S, Ludvigsson J, Hammar M, Dahlgren L-O, Faresjo T. Twenty years experiences of interprofessional education in Linkoping-ground-breaking and sustainable. J Interprof Care. 2009;23:121-33. doi:10.1080/13561820902728984.

60. Wilhelmsson M, Svensson A, Timpka T, Faresjö T. Nurses' views of interprofessional education and collaboration: A comparative study of recent graduates from three universities. J Interprof Care. 2013;27:155-60. doi:10.3109/13561820.2012.711787.

61. LongStl Freiburg. https://www.interprof.uni-freiburg.de/.

62. Straub C, Krüger M, Bode S. Interprofessional education in pediatrics-Child protection and family services as a teaching example. Ann Anat. 2017;213:62-8. doi:10.1016/j.aanat.2017.04.003.

63. Mahler C, Berger SJ, Karstens S, Campbell S, Roos M, Szecsenyi J. Re-profiling today's health care curricula for tomorrow's workforce: Establishing an interprofessional degree in Germany. J Interprof Care. 2015;29:386-8. doi:10.3109/13561820.2014.979980.

64. Mette M, Dölken M, Hinrichs J, Narciß E, Schüttpelz-Brauns K, Weihrauch U, Fritz HM. Comprehension through cooperation: Medical students and physiotherapy apprentices learn in teams - Introducing interprofessional learning at the University Medical Centre Mannheim, Germany. GMS J Med Educ. 2016;33:Doc31. doi:10.3205/zma001030.

65. HIPSTA. 2018. https://www.bosch-stiftung.de/sites/default/files/documents/201801/Kurzbeschreibung_HIPSTA.pdf.

66. In Kooperation be-greifen. 2018. https://www.bosch-stiftung.de/sites/default/files/documents/201803/Projektbeschreibung_dt.pdf.

67. IPAPÄD. 2018. http://www.bosch-stiftung.de/sites/default/files/documents/201801/IPAPAED_Freiburg_Kurzbeschreibung.pdf.

68. Mihaljevic AL, Schmidt J, Mitzkat A, Probst P, Kenngott T, Mink J, et al. Heidelberger Interprofessionelle Ausbildungsstation (HIPSTA): A practice- and theory-guided approach to development and implementation of Germany's first interprofessional training ward. GMS J Med Educ. 2018;35:Doc33. doi:10.3205/zma001179. 
69. Robert-Bosch-Stiftung. Operation Team. 2018. https://www.boschstiftung.de/sites/default/files/documents/2018-03/037_18-03-29_0PTeam_Lehrkonzepte_WEB_ES.pdf.

70. Zirn L, Körner M, Luzay L, Sandeck F, Müller-Fröhlich C, Straub C, et al. Design and evaluation of an IPE module at the beginning of professional training in medicine, nursing, and physiotherapy. GMS J Med Educ. 2016;33:Doc24. doi:10.3205/zma001023.

71. Tume LN, Sefton G, Arrowsmith P. Teaching paediatric ward teams to recognise and manage the deteriorating child. Nurs Crit Care. 2014;19:196-203. doi:10.1111/nicc.12050.

72. Zanotti R, Sartor G, Canova C. Effectiveness of interprofessional education by on-field training for medical students, with a pre-post design. BMC Med Educ. 2015;15:121. doi:10.1186/s12909-0150409-z.

\section{Figures}

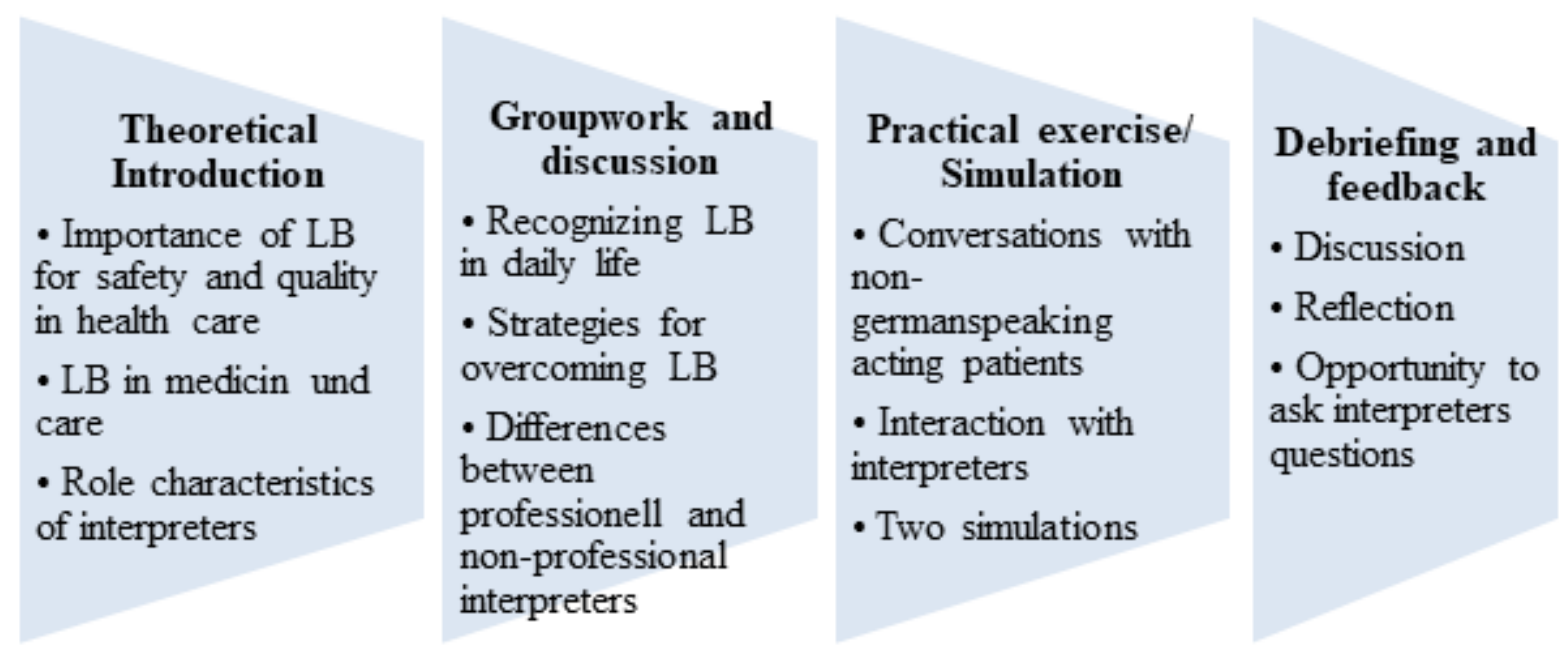

Figure 1

Content and Structure of the course 


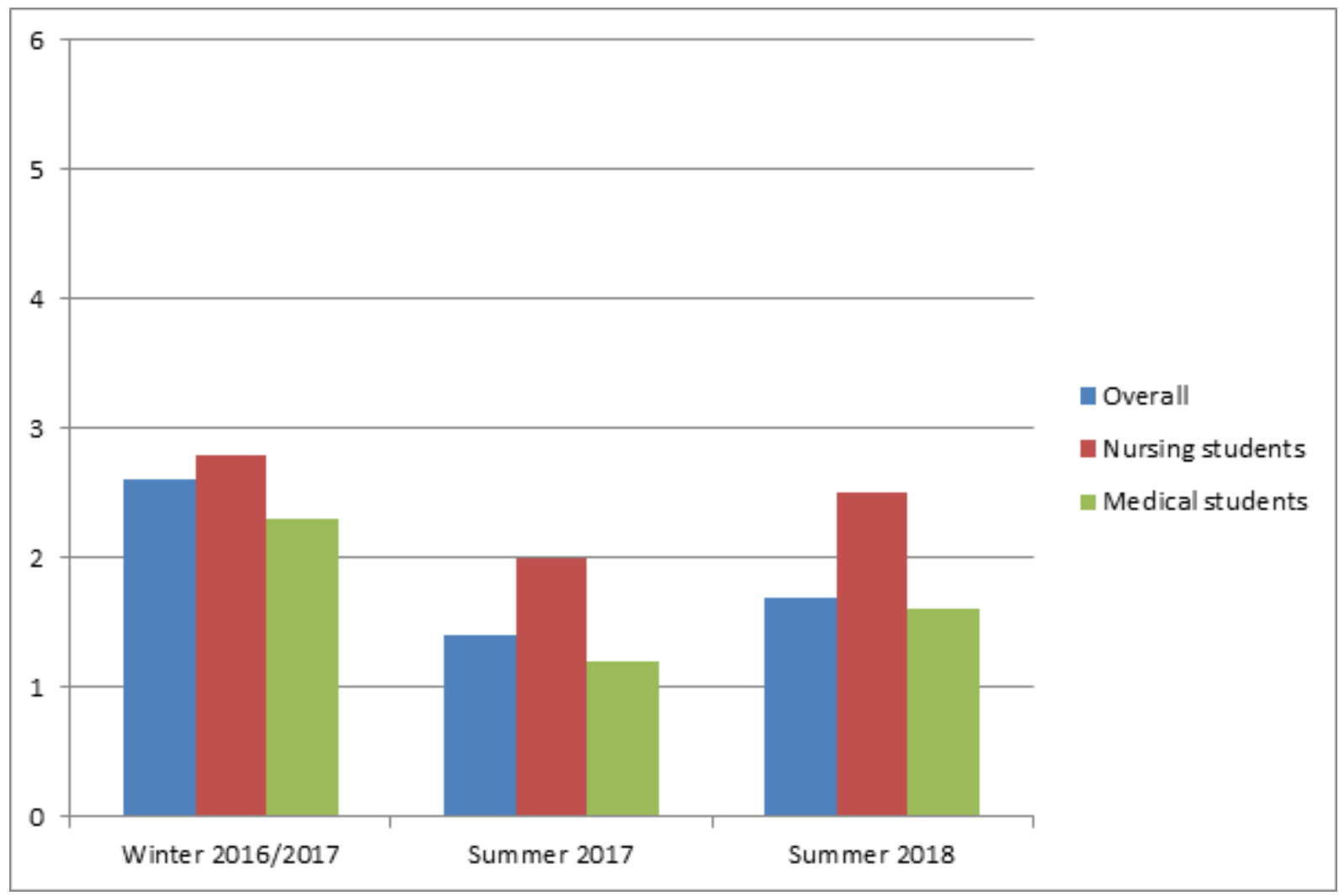

Figure 2

Evaluation (School grades 1-6, 1=very good, 6 = insufficient)

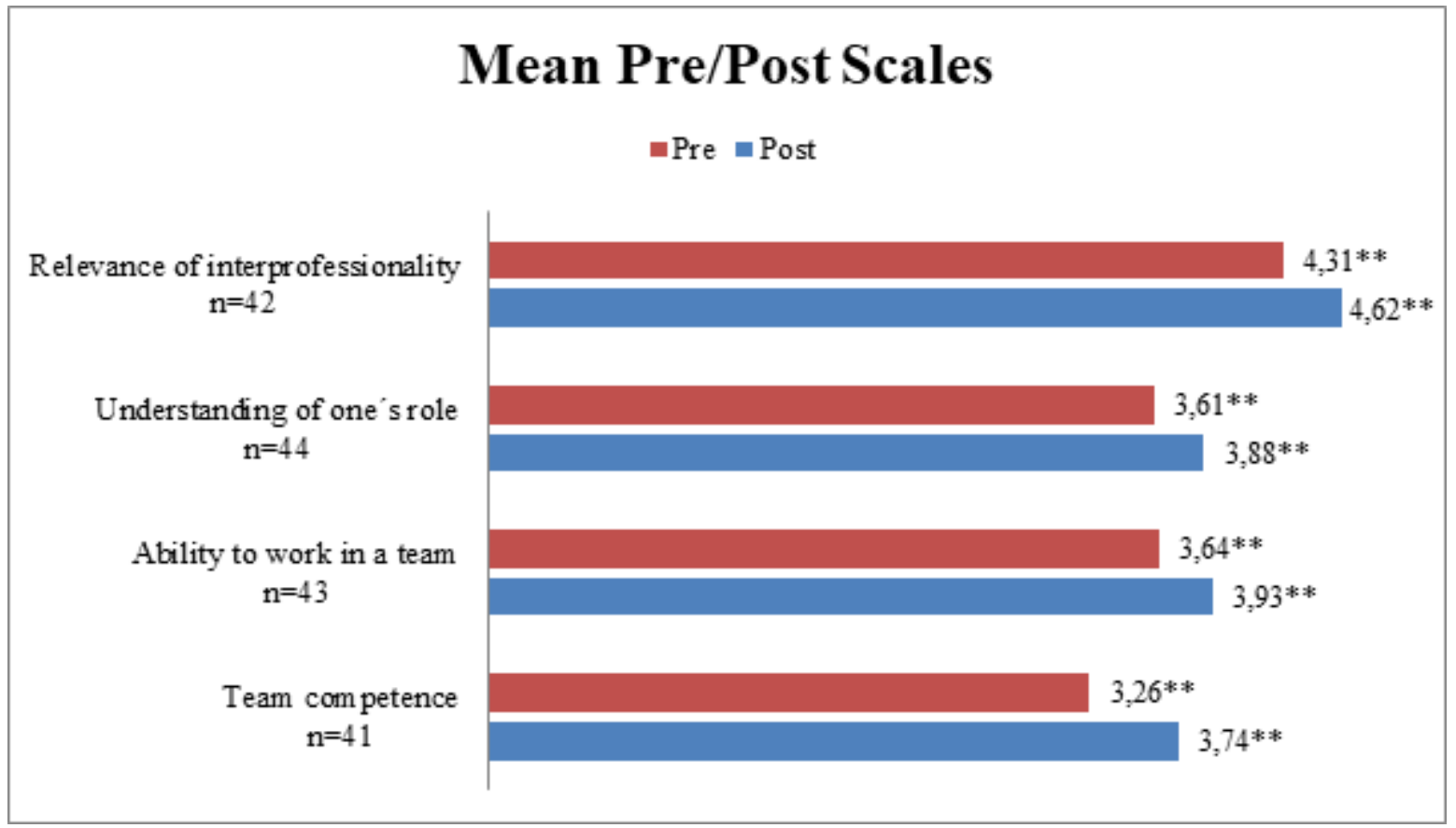

Figure 3

Mean Pre/Post of scale 


\section{Supplementary Files}

This is a list of supplementary files associated with this preprint. Click to download.

- AppendicesBMCMedEducation.docx 